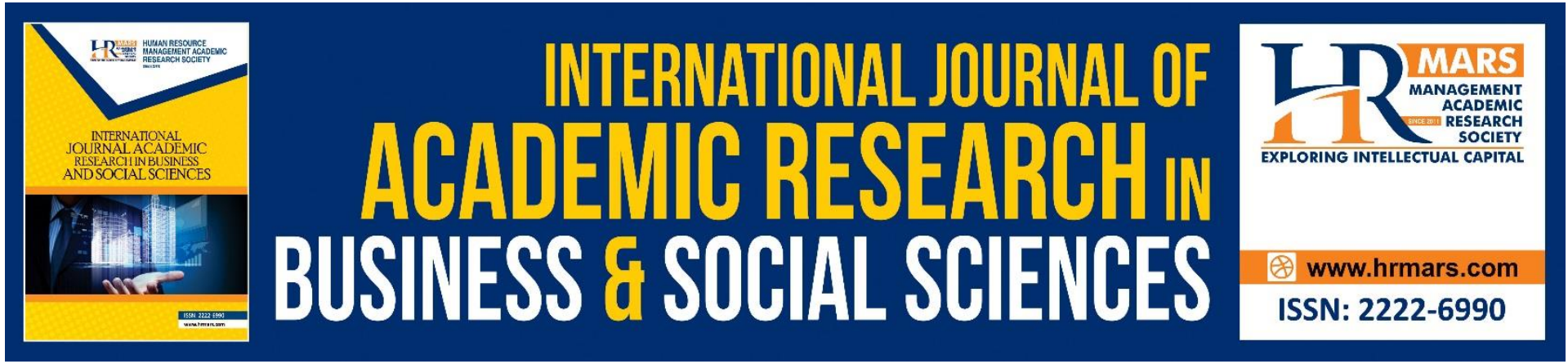

\title{
Improving Patient Satisfaction at Paediatric Outpatient Clinic Services, Hospital Tuanku Fauziah
}

Haslizawati Hashim, Beni Widarman Yus Kelana, Teo Poh Chuin

To Link this Article: http://dx.doi.org/10.6007/IJARBSS/v11-i8/10826

DOI:10.6007/IJARBSS/v11-i8/10826

Received: 10 June 2021, Revised: 19 July 2021, Accepted: 05 August 2021

Published Online: 14 August 2021

In-Text Citation: (Hashim et al., 2021)

To Cite this Article: Hashim, H., Kelana, B. W. Y., \& Chuin, T. P. (2021). Improving Patient Satisfaction at Paediatric Outpatient Clinic Services, Hospital Tuanku Fauziah. International Journal of Academic Research in Business and Social Sciences, 11(8), 1185-1194.

Copyright: (c) 2021 The Author(s)

Published by Human Resource Management Academic Research Society (www.hrmars.com)

This article is published under the Creative Commons Attribution (CC BY 4.0) license. Anyone may reproduce, distribute, translate and create derivative works of this article (for both commercial and non-commercial purposes), subject to full attribution to the original publication and authors. The full terms of this license may be seen at: http://creativecommons.org/licences/by/4.0/legalcode

Vol. 11, No. 8, 2021, Pg. 1185 - 1194

http://hrmars.com/index.php/pages/detail/IJARBSS

JOURNAL HOMEPAGE

Full Terms \& Conditions of access and use can be found at http://hrmars.com/index.php/pages/detail/publication-ethics 


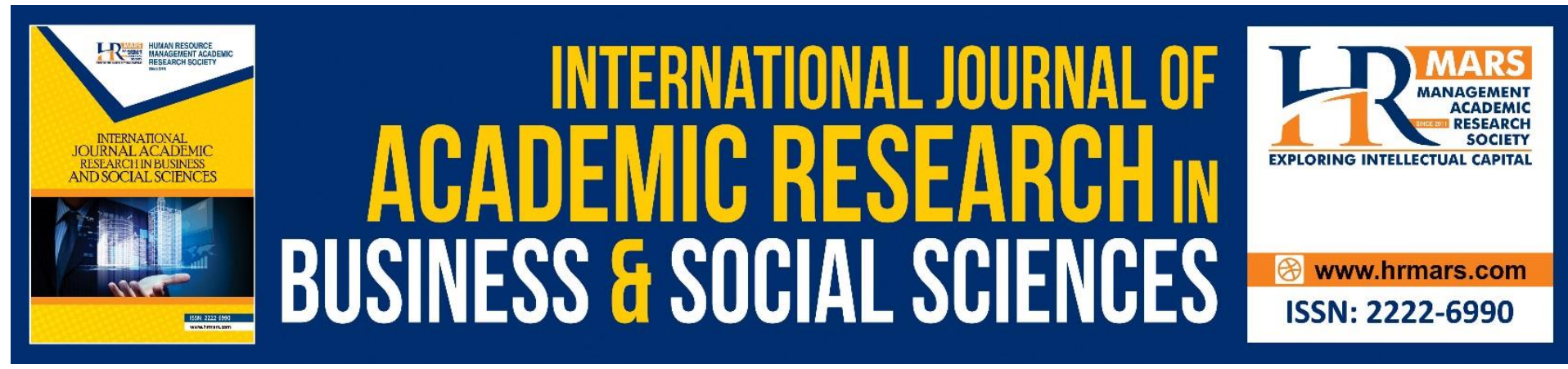

\title{
Improving Patient Satisfaction at Paediatric Outpatient Clinic Services, Hospital Tuanku Fauziah
}

\section{Haslizawati Hashim, Beni Widarman Yus Kelana, Teo Poh Chuin}

Azman Hashim International Business School, Universiti Teknologi Malaysia Email: hasliza77@yahoo.com, beni@utm.my, pohchuin@utm.my

\begin{abstract}
This article aims to give an overview of the importance of customer satisfaction. In the context of the healthcare setting, patient satisfaction remains a useful indicator to measure customer satisfaction. Hence, reflecting the quality of healthcare services. Customer expectation and experience play an important role in determining customer satisfaction. Customer satisfaction is the degree to which the products or services provided by the organisation meet the expectation and how is their experience with the products or services. This article emphasised the relationship between customer expectations and experience with customer satisfaction at outpatient clinic services based on previous literature. The reliability and validity of the research instruments used to measure customer satisfaction in this study are discussed to ensure that the research instrument has high reliability and validity. Thus, proving that measuring patient expectation and the patient experience level is important in determining customer satisfaction at outpatient clinic services. The findings of this study revealed that all variables of this study are of high reliability and validity.
\end{abstract}

Keywords: Customer Expectation, Customer Experience, Customer Satisfaction.

\section{Introduction}

Patient satisfaction is a subjective and complicated phenomenon yet it directly reflects the competency of the hospital or other healthcare facilities and has been used globally. Satisfaction is used as an indicator of the service delivery quality and help health care service providers and organization to build a better understanding of the patients' needs and to improve services provided (Hussain et al., 2019). Many healthcare organizations around the world are moving towards patient-centred care which is defined as "providing care that is respectful of and responsive to individual patient preferences, needs, and values and ensuring that patient values guide all clinical decisions" (Kuipers et al., 2019). Patient satisfaction surveys are being increasingly identified to be a benchmark to measure the success of the service delivery system functional at hospitals. Hence, patient satisfaction is considered a valid indicator of the quality of care.

Higher patient satisfaction gives benefits to a healthcare organization in terms of achieving customers retention and customers loyalty. Patient satisfaction also will provide 
consistent profitability, especially to the private healthcare sector. Furthermore, patient satisfaction increases staff morale, increased personal and professional satisfaction, reduced staff turnover. Hence, leads to increased work productivity (Winland, 2000). The purpose of this article is to provide valuable opinions on patient expectations and patient experience are determinants of patient satisfaction. besides to demonstrate that the instrument is highly reliable.

\section{Problem Statement}

Patients satisfaction is a subjective and complicated phenomenon yet it directly reflects the competency of the hospital or other healthcare facilities and has been used globally (Al-Neyadi et al., 2018; Yunus et al., 2013). There are many factors affecting patients' satisfaction including waiting time, consultation time, the attitudes of doctors and other health staff, service costs, hospital infrastructure, physical comforts such as the cleanliness of the facility, emotional support, respect for patient preferences and availability of medicine (Sodani et al., 2010).

The increasing number of paediatric patients at the Paediatric Outpatient Clinic leads to various factors that would lead to low patients' satisfaction such as longer waiting times, shorter consultation time, increased staff workload leading to increased stress, thus reduced staff performance or services attitude. the children visiting the Paediatric Outpatient Clinic also are with distinctive physical, emotional and mental developmental stages. Hence it becomes difficult to determine the quality of outcome regarding healthcare (Sengupta et al., 2019). Most paediatric patients are depending on the parents/guardian; thus, any issue or complaints will be expressed by the parents; although some children are independent to voice out their opinion. Therefore, paediatric healthcare satisfaction is a result of the complex and remarkable relationship being shared by the physician, parent/caregiver and the patient (Sengupta et al., 2019). 


\section{Problem Diagnosis}

The Fishbone diagram in Figure 1.1 identified the root cause or issues that potentially contribute to the lower patient satisfaction at the Paediatric Outpatient Clinic services, HTF.

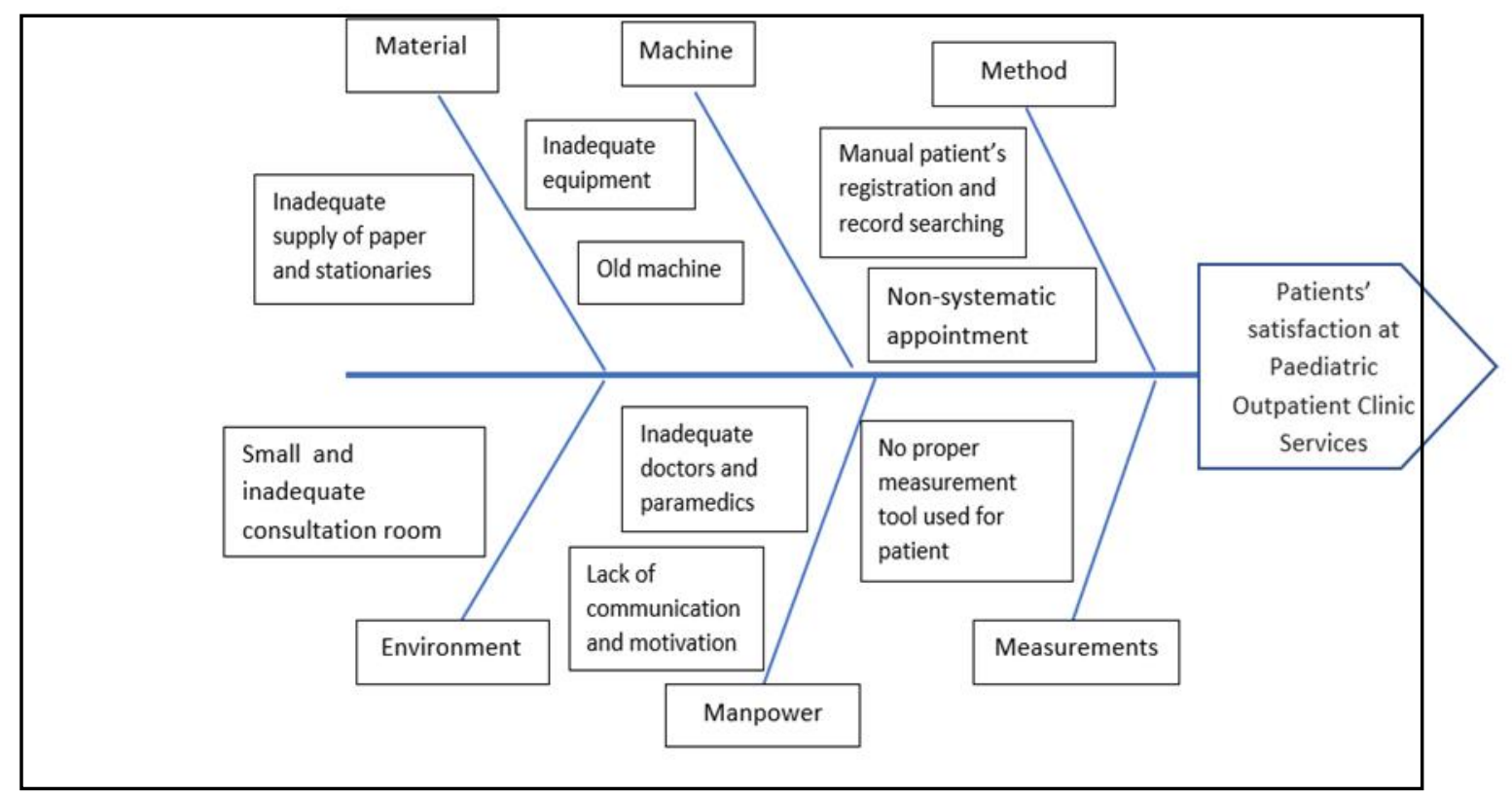

Figure 1.1: Fishbone Diagram of factor affecting patient satisfaction at Paediatric Outpatient Clinic Services, HTF

The complicated method whereby most of the work processes were performed manually as well as non-systematic appointments were the main issues identified to the cause of ineffective services. Ineffective healthcare provider-patient communication is also a known contributing factor to customer dissatisfaction. The other contributing factors are inadequate human resources, inadequate basic facilities as well an unappealing working environment. Currently, there are no proper measurement tools to measure customer satisfaction toward the clinic services.

\section{Significance of the Research}

The importance of this study is to understand issues related to healthcare service quality as well as contribute to the development of knowledge in a field of study. For the past 20 years, the patient satisfaction survey has become an important tool for identifying gaps and develop an effective action plan for the improvement of healthcare quality services (AlAbri \& Al-Balushi, 2014). As Malaysia healthcare services are moving towards patient-centred care, thus patient satisfaction study is very important as it reflects the patient's decisionmaking involvement in improving the healthcare services. The finding of this study would give opportunity and benefit to the organization to improve performance.

Furthermore, the instrument used in this study shall become a standard tool for future customer satisfaction surveys of outpatient clinic services as well as guidance for other researchers as a reference in the future who wish to study a similar research field, hence further improvement can be implemented. 


\section{Literature Review}

The main objective of any health care organization is to deliver the best possible health care to patients. The study of patient satisfaction with health care services received is of most importance in the context of providing quality patient care services (Rajkumari \& Nula, 2017). Satisfaction is used as an indicator of the service delivery quality and help health care service providers and organization to build a better understanding of the patients' needs and to improve services provided (Hussain et al., 2019). Patient satisfaction surveys are being increasingly identified to be a benchmark to measure the success of the service delivery system functional at hospitals. There were many definitions of customers in the healthcare organization. McKillip, 2017, defined healthcare customers as external and internal customers. external customers include patients, patient's families and relatives, referring physicians, doctors' offices, blood donors, insurance companies and other agencies. While internal customers include all the staff in the healthcare organizations such as physicians, nurses, and other professionals and committees. Meanwhile, Zhang et al., 2017 described patients as customers in their study of customer identification in healthcare. In this study, patients were classified as customers of the specialist outpatient clinic, Hospital Tuanku Fauziah.

\section{Customer Satisfaction}

Customer satisfaction is defined as perception developed when consuming the product or services, whether it meets the consumer expectation (Chalikias et al., 2016). In the healthcare industry, patients, in general, are consumers of healthcare services. The previous studies highlighted various factors affecting customer satisfaction in healthcare organizations including in hospital and clinic services. Service quality was identified as the most important factor determining customer satisfaction in healthcare (Allahham, 2013; Batbaatar et al., 2017). There are many approaches to evaluate service quality in the healthcare setting. The most widely used known as the SERVQUAL model which consists of 5 dimensions which are tangibles, involved external factors such as physical facility, equipment, and staff appearance; reliability, the ability to provide services accurately to customers (patients) as promised; responsiveness, the attitude of healthcare providers who provide prompt service to the patient; assurance, the knowledge and courtesy of healthcare providers and the ability to deliver trust and confidence on their qualification and competence; and finally empathy, the individual attention and caring attitudes towards each patient (Hafiz et al., 2011; Lee \& Kim, 2017). Therefore, these dimensions were used as a guide to measuring customer satisfaction in various healthcare organizations.

\section{Customer Expectation and Customer Satisfaction}

Customer expectation is a customer perception toward the product or services provided whether meeting their needs, exceeding beyond the needs or lower than their assumption. Customer expectation is subjective and it differs between each customer. Customer expectation is closely related to customer satisfaction. Previous studies accentuated the significant effect of customer expectation on customer satisfaction (Almsalam, 2014; Chan et al., 2003). The customer may have low satisfaction if the services received did not meet their expectation. In contrast, the customer is satisfied if the services have met their expectation or achieved beyond the expectation. The Healthcare industry is highly competitive and because of improving socio-economic, education and advanced technology, the customer's demand and expectations are also in a rising trend. Therefore, 
customer satisfaction is increasingly identified to be an established indicator to measure the success of healthcare services (Mohd \& Chakravarty, 2014).

\section{Customer Experience and Customer Satisfaction}

A positive customer experience is very crucial and a critical component in ensuring customer loyalty, retention and encourage brand reputation. In the healthcare setting, patient experience is an interaction of patient/customer with the healthcare system including care from doctors, nurses, other staff, facilities and other services. Bowling et al., in 2012 described patients' experiences as "their direct, personal observations of their healthcare" and measured patient experience in terms of whether patient 'expectations' were met. Enhancing patient's experience is associated with positive quality outcomes including patient safety and clinical effectiveness (Ahmed et al., 2014). Expectations of experience include cleanliness of the facilities, clear information and signage, convenient and punctual appointments, helpful reception staff, knowledgeable and reassurance doctors with respect and empathy to patients, offering patient-centred care whereby a patient receiving a throughout information on their health condition, benefits and side effects of treatment, being allowed to be involved in their treatment decisions. Hence, customer satisfaction is an outcome measure of a patient's experiences of care, in addition to clinical outcomes and confidence in the health system (Larson et al., 2019). Bleich et al., in 2009 reported that patient experience was significantly associated with satisfaction with the healthcare system and explained $10.4 \%$ of the variation around the concept of satisfaction. Furthermore, a good understanding of the patient experience will provide clear guidance for further research, as well as guiding healthcare policymakers for consistent and sustainable improvements in medical care quality (Oben, 2020).

\section{Methods}

This study is using the quantitative method. The study involved 43 patients attending Medical Outpatients Clinic which has a similar setting to the Paediatric Outpatient Clinic. The researcher obtained permission to conduct the study from the Head of the Medical Department before the commencement of the study. The questionnaire is distributed among patients attending the Medical Outpatients Clinic. To further analysed the reliability of the questionnaire, the researcher conducted a reliability analysis through SPSS 23 whereby two variables which are patient's expectation and patient's experience were tested. Table 1 exhibit the variables of the instrument used in this study.

Table 1: Research Variables

\begin{tabular}{|l|l|}
\hline Variables & Items \\
\hline Patient expectation & 12 \\
\hline Patient experience & 13 \\
\hline
\end{tabular}

\section{Results of Normality and Reliability Test}

The results of data assessment for normality and reliability of the instrument are discussed below:

\section{Normality Test}

Assessment of data normality is essential to determine whether the data set is normally distributed and is an underlying assumption for using parametric statistical tests. 
The normality test for the pilot study was statistically analysed using SPSS 23 . The mean $z$ value for the variable patient expectation of the pilot study was between -1.67 to +1.12 while the $z$ value for variable patient experience was between -2.02 to +1.34 . The $z$ value between -4.0 to +4.0 is acceptable (Chua, 2011).

Table 2: Normality Test

\begin{tabular}{|c|c|c|c|c|}
\hline \multicolumn{5}{|l|}{ Descriptive } \\
\hline \multirow[t]{13}{*}{ Expectation } & \multicolumn{2}{|l|}{ Mean } & 4.43 & .078 \\
\hline & \multirow{2}{*}{$\begin{array}{l}\text { 95\% Confidence Interval for } \\
\text { Mean }\end{array}$} & Lower Bound & 4.27 & \\
\hline & & Upper Bound & 4.59 & \\
\hline & \multicolumn{2}{|l|}{ 5\% Trimmed Mean } & 4.46 & \\
\hline & \multicolumn{2}{|l|}{ Median } & 4.50 & \\
\hline & \multicolumn{2}{|l|}{ Variance } & .259 & \\
\hline & \multicolumn{2}{|l|}{ Std. Deviation } & .508 & \\
\hline & \multicolumn{2}{|l|}{ Minimum } & 3 & \\
\hline & \multicolumn{2}{|l|}{ Maximum } & 5 & \\
\hline & \multicolumn{2}{|l|}{ Range } & 2 & \\
\hline & \multicolumn{2}{|l|}{ Interquartile Range } & 1 & \\
\hline & \multicolumn{2}{|l|}{ Skewness } & -.605 & .365 \\
\hline & \multicolumn{2}{|l|}{ Kurtosis } & -.194 & .717 \\
\hline \multirow[t]{13}{*}{ Experience } & \multicolumn{2}{|l|}{ Mean } & 3.97 & .074 \\
\hline & \multirow{2}{*}{$\begin{array}{l}\text { 95\% Confidence Interval for } \\
\text { Mean }\end{array}$} & Lower Bound & 3.82 & \\
\hline & & Upper Bound & 4.12 & \\
\hline & \multicolumn{2}{|l|}{ 5\% Trimmed Mean } & 3.99 & \\
\hline & \multicolumn{2}{|l|}{ Median } & 4.08 & \\
\hline & \multicolumn{2}{|l|}{ Variance } & .231 & \\
\hline & \multicolumn{2}{|l|}{ Std. Deviation } & .481 & \\
\hline & \multicolumn{2}{|l|}{ Minimum } & 3 & \\
\hline & \multicolumn{2}{|l|}{ Maximum } & 5 & \\
\hline & \multicolumn{2}{|l|}{ Range } & 2 & \\
\hline & \multicolumn{2}{|l|}{ Interquartile Range } & 1 & \\
\hline & \multicolumn{2}{|l|}{ Skewness } & -.547 & .365 \\
\hline & \multicolumn{2}{|l|}{ Kurtosis } & -.213 & .717 \\
\hline
\end{tabular}

The normality testing used for this study was through numerical statistical methods as shown in Table 2, which is skewness and kurtosis. As for normal data distribution, the value for skewness and kurtosis must be between -2.0 to +2.0 (Chua, 2013). In this study, the skewness and kurtosis value of the patient expectation variable was -0.605 and -0.194 , while the skewness and kurtosis value of the patient experience variable was -0.547 and -0.213 . Therefore, the skewness and kurtosis values of both variables are normally distributed.

\section{Reliability}

Research reliability is the degree to which the research method produces stable and consistent results. If the same result can be consistently achieved by using the same methods 
under the same circumstances, the measurement is considered reliable. Reliability is concerned with the consistency of questionnaires (Saunders et al., 2009). In this study, internal consistency is used for the reliability measure for the questionnaire.

\section{Cronbach's Alpha}

The internal consistency is estimated via Cronbach's alpha coefficient index, which is the most commonly used form to determine the internal consistency of an instrument (Heale \& Twycross, 2015). In general, a score of 0.7 and higher is acceptable reliability.

To further analysed the reliability of the questionnaire, the reliability analysis was conducted through SPSS 23 whereby two variables which are patient's expectation and patient's experience were tested. The Cronbach's alpha value for the patient's expectation variable in this study was 0.940 and the value for the patient's experience variable was 0.898 (Table 3.10). therefore, both variables showed excellent reliability.

Table 3: Cronbach's Alpha of the Study

\begin{tabular}{|l|l|l|}
\hline \multirow{2}{*}{ Variables } & Reliability Statistics \\
\cline { 2 - 3 } & Cronbach's Alpha & No. of items \\
\hline Patient's Expectation & 0.940 & 12 \\
\hline Patient's Experience & 0.898 & 13 \\
\hline
\end{tabular}

\section{Conclusion}

This article provides an overview of the importance of positive customer expectations and the customer experience in determining customer satisfaction. Customer satisfaction in healthcare services is a response to the patient evaluation of the healthcare provider service quality based on their consumption experience. Hence, indicates that customer satisfaction is an important element in measuring service quality in an organization or business including in healthcare services. Furthermore, the result of this study demonstrates that the instrument is reliable and can be utilized in studying the relationship between customer expectation and the customer experience in determining customer satisfaction. Finally, the study finding also contributed to the knowledge in addition to the existing literature of a similar study field and shall benefit other researchers as a reference in the future.

\section{Acknowledgement}

I wish to express my sincere gratitude to Universiti Teknologi Malaysia (UTM) and Azman Hashim International Business School, for the opportunity for conducting this action research as part of the requirement of the Master of Business Administration program and for providing various guidance and assistance. I would like to thank the Ministry of Health Malaysia (MOH) and Hospital Tuanku Fauziah especially the staff and patients of Paediatric and Medical Outpatient Clinics for the support and willingness to participate in this research. Their involvement and contribution mean a lot in my data collection process whereby I managed to collect relevant and quality data and suggestions with their assistance although in facing the COVID-19 pandemic. Lastly, I would like to express my gratitude to Dr Siti Akma bin Ishak, the Head of the Paediatric Department and my supervisor, Dr Beni Widarman bin Yus Kelana, for the invaluable guidance and assistance throughout this research process. I am truly honoured to receive their support. 


\section{References}

Ahmed, F., Burt, J., \& Roland, M. (2014). Measuring patient experience: Concepts and methods. Patient, 7(3), 235-241. https://doi.org/10.1007/s40271-014-0060-5

Al-Abri, R., \& Al-Balushi, A. (2014). Patient satisfaction survey as a tool towards quality improvement. Oman Medical Journal, 29(1), 3-7. https://doi.org/10.5001/omj.2014.02

Allahham, A. (2013). Determinants of Customer Satisfaction in Healthcare Services. International Journal of Business and Management Invention ISSN, 2(12), 59-63. www.ijbmi.org

Al-Neyadi, H. S., Abdallah, S., \& Malik, M. (2018). Measuring patient's satisfaction of healthcare services in the UAE hospitals: Using SERVQUAL. International Journal of Healthcare Management, 11(2), 96-105. https://doi.org/10.1080/20479700.2016.1266804

Almsalam, S. (2014). The Effects of Customer Expectation and Perceived Service Quality on Customer Satisfaction Samaan. International Journal of Business and Management Invention, 3(8), 79-84. https://doi.org/10.19030/jabr.v31i4.9328

Batbaatar, E., Dorjdagva, J., Luvsannyam, A., Savino, M. M., \& Amenta, P. (2017). Determinants of patient satisfaction: A systematic review. In Perspectives in Public Health (Vol. 137, Issue 2, pp. 89-101). https://doi.org/10.1177/1757913916634136

Bleich, S. N., Ozaltin, E., \& Murray, C. J. L. (2009). How does satisfaction with the healthcare system relate to patient experience? Bulletin of the World Health Organization, 87(4), 271-278. https://doi.org/10.2471/BLT.07.050401

Chalikias, M., Drosos, D., Skordoulis, M., \& Tsotsolas, N. (2016). Determinants of customer satisfaction in the healthcare industry: The case of the Hellenic Red Cross. International Journal of Electronic Marketing and Retailing, 7(4), 311-321.

https://doi.org/10.1504/IJEMR.2016.080807

Chan, L. K., Hui, Y. V., Lo, H. P., Tse, S. K., Tso, G. K. F., \& Wu, M. L. (2003). Consumer satisfaction index: new practice and findings. European Journal of Marketing, 37(5/6), 872-909. https://doi.org/10.1108/03090560310465189

Hafiz, M., Rashid, A., Azlina, A., Muhammad, M., \& Hamzah, I. (2011). Service Quality and Patients' Satisfaction in Healthcare Service in Malaysia. International Journal of Customer Service Management, 1(1), 41-49.

Heale, R., \& Twycross, A. (2015). Validity and reliability in quantitative studies. Evidence-Based Nursing, 18(3), 66-67. https://doi.org/10.1136/eb-2015-102129

Hussain, A., Asif, M., Jameel, A., \& Hwang, J. (2019). Measuring OPD patient satisfaction with different service delivery aspects at public hospitals in Pakistan. International Journal of Environmental Research and Public Health, 16(13).

https://doi.org/10.3390/ijerph16132340

Kuipers, S. J., Cramm, J. M., \& Nieboer, A. P. (2019). The importance of patient-centred care and co-creation of care for satisfaction with care and physical and social well-being of patients with multi-morbidity in the primary care setting. BMC Health Services Research, 19(1), 1-9. https://doi.org/10.1186/s12913-018-3818-y

Larson, E., Sharma, J., Bohren, M. A., \& Tunçalp, Ö. (2019). When the patient is the expert: Measuring patient experience and satisfaction with care. Bulletin of the World Health Organization, 97(8), 563-569. https://doi.org/10.2471/BLT.18.225201

Lee, D., \& Kim, K. K. (2017). Assessing healthcare service quality: a comparative study of patient treatment types. International Journal of Quality Innovation, 3(1), 1-15. https://doi.org/10.1186/s40887-016-0010-5 
McKillip, R. M. (2017). Customer service. Vertiflite, 63(2), 3. https://doi.org/10.1201/9781351049221-8

Mohd, A., \& Chakravarty, A. (2014). Patient satisfaction with services of the outpatient department. Medical Journal Armed Forces India, 70(3), 237-242. https://doi.org/10.1016/j.mjafi.2013.06.010

Oben, P. (2020). Understanding the Patient Experience: A Conceptual Framework. Journal of Patient Experience, 7(6), 906-910. https://doi.org/10.1177/2374373520951672

Rajkumari, B., \& Nula, P. (2017). Patient's satisfaction with care in a government health facility in North East India: A cross-sectional study. JMS - Journal of Medical Society, 31(2), 9498. https://doi.org/10.4103/jms.jms_81_16

Sengupta, M., Chakrabarti, S., \& Mukhopadhyay, I. (2019). Waiting Time: The Expectations and Preferences of Patients in a Paediatric OPD. Journal of Health Management, 21(3), 427-442. https://doi.org/10.1177/0972063419868586

Sodani, P. R., Kumar, R. K., Srivastava, J., \& Sharma, L. (2010). Measuring patient satisfaction: A case study to improve quality of care at public health facilities. Indian Journal of Community Medicine, 35(1), 52-56. https://doi.org/10.4103/0970-0218.62554

Winland, R. D. (2000). Patient satisfaction. General Dentistry, 48(1), 8. https://doi.org/10.4103/0974-2077.74491

Yunus, N. M., Latiff, D. S. A., Din, S. C., \& Ma'on, S. N. (2013). Patient Satisfaction with Access to 1Malaysia Clinic. Procedia - Social and Behavioral Sciences, 91, 395-402. https://doi.org/10.1016/j.sbspro.2013.08.436

Zhang, L., Zhang, Y., Jiang, H., Yang, M. M., Huang, Y. Y., \& Li, S. J. (2017). Customer identification in the healthcare industry. International Journal of Market Research, 59(6), 803-822. https://doi.org/10.2501/IJMR-2017-054 